\title{
Implementasi Data Mining Penjualan Produk Kosmetik Pada PT. Natural Nusantara Menggunakan Algoritma Apriori
}

\author{
Fajar Adhinda Kusuma Wardani ${ }^{1}$, Titin Kristiana ${ }^{2}$ \\ ${ }^{1}$ STMIK Nusa Mandiri \\ Email: fajaradhinda@gmail.com \\ ${ }^{2}$ STMIK Nusa Mandiri \\ Email: titin.tka@nusamandiri.ac.id
}

\begin{abstract}
Women's life can not be separated from cosmetics. In addition to beautifying themselves, cosmetics are also used for health purposes. Cosmetics are basically one of the basic needs of women. Every day the sales transaction data at PT. Natural Nusantara is increasing and causing huge data storage. Most sales transaction data is only used as archives without being used properly. The data should be used to see the relevance of each item purchased by consumers simultaneously. This research analyzes data using a priori algorithm method, with this method it is known that cosmetic products purchased simultaneously and most sold by looking at the value of support and confidence. In the process of data processing using manual calculation and RapidMiner 5.3 software to analyze datasets at PT. Natural Nusantara. The results of this study use 10\% support and 50\% confidence. This study produced 7 rules for association rules.
\end{abstract}

Keywords: Cosmetic Products, Sales, Apriori Algorithm, Association Rule.

\section{PENDAHULUAN}

Kehidupan wanita tak lepas dari kosmetik. Selain untuk mempercantik diri, kosmetik juga digunakan untuk tujuan kesehatan. Mulai dari mengatasi jerawat, melindungi kulit dari efek buruk sinar matahari, menghidrasi dan menutrisi kulit, serta melawan tanda-tanda penuaan. Salah satu perusahaan yang mengeluarkan produk kosmetik adalah PT. Natural Nusantara (NASA). PT. Natural Nusantara merupakan sebuah perusahaan yang memiliki konsep produk-produk yang terbuat dari bahan organik herbal dan merupakan hasil karya dari negeri sendiri dan bukan import.

Setiap hari data transaksi penjualan akan terus bertambah dan menyebabkan penyimpanan data yang sangat besar. Kebanyakan data transaksi penjualan hanya dijadikan arsip saja tanpa dimanfaatkan dengan baik. Padahal kumpulan data tersebut memiliki informasi yang sangat bermanfaat. Permasalahan yang sering muncul yaitu peletakkan barang-barang yang tidak sesuai dengan perilaku kebiasaan konsumen dalam membeli barang secara bersamaan dalam satu waktu. Hal ini tentu akan mempengaruhi tingkat penjualan barang.

Berdasarkan masalah diatas, maka diperlukan teknik data mining dengan menggunakan algoritma apriori. Algoritma apriori bertujuan untuk mengetahui pola kombinasi item dan itemset frekuensi tinggi, lalu diuji apakah kombinasi tersebut memenuhi parameter minimum support dan confidence yang merupakan nilai ambang yang diberikan user.

\section{Identifikasi Masalah}

Berdasarkan latar belakang masalah diatas, maka identifikasi masalah yang diambil adalah :

1. Bagaimana menerapkan algoritma apriori untuk mengetahui penjualan produk paling banyak terjual ?

2. Bagaimana mengimplementasikan algoritma apriori pada penjualan produk kosmetik dengan menggunakan software RapidMiner 5.3 ?

\section{Maksud dan Tujuan}

Adapun maksud dan tujuan dalam penelitian ini sebagai berikut :

1. Untuk mengetahui sejauh mana algoritma apriori dapat membantu mengetahui pola kombinasi penjualan produk PT. Natural Nusantara.

2. Untuk mengetahui sejauh mana algoritma apriori membantu dalam strategi pemasaran.

3. Untuk mengetahui nilai minimum support dan confidence dari data penjualan produk sehingga dapat diketahui produk apa saja yang banyak terjual.

\section{Data Mining}

Data mining merupakan proses iterative dan interaktif untuk menemukan pola atau model baru 
yang sempurna, bermanfaat dan dapat dimengerti dalam suatu database yang sangat besar (massive database). Data mining berisi pencarian trend atau pola yang diinginkan dalam database besar untuk membantu pengambil keputusan diwaktu yang akan datang, pola-pola ini dikenali perangkat tertentu yang dapat memberikan suatu analisa data yang berguna dan berwawasan yang kemudian dapat dipelajari dengan lebih teliti, yang mungkin saja menggunakan perangkat pendukung keputusan yang lain (Sikumbang, 2018).

\section{Algoritma Apriori}

Algoritma apriori adalah algoritma yang paling terkenal unuk menemukan pola frekuensi tinggi. Apriori dibagi menjadi beberapa tahap disebut narasi atau pass. Pembentukan kandidat itemsets, kandidat k-itemsets dibentuk dari kombinasi (k-1)-itemsets yang didapat dari iterasi sebelumnya. Satu cara dari algoritma apriori adalah adanya pemangkasan kandidat k-itemset yang subset-nya yang berisi k-1 item tidak termasuk dalam pola frekuensi tinggi dengan panjang k-1. Algoritma apriori terkenal untuk menemukan pola frekuensi tinggi. Proses pembentukan pola kombinasi itemsets dan pembuatan rules dimulai dari analisis data (Purnia \& Warnilah, 2017)

1. Pembentukan kandidat itemset, kandidat kitemset dibentuk dari kombinasi (k-1)-itemset yang didapat dari iterasi sebelumnya. Satu cara dari algoritma apriori adalah adanya pemangkasan kandidat k-itemset yang subset-nya yang berisi $\mathrm{k}-1$ item tidak termasuk dalam pola frekuensi tinggi dengan panjang $\mathrm{k} 1$.

2. Penghitungan support dari tiap kandidat kitemset. Support dari tiap kandidat k-itemset didapat dengan menscan database untuk menghitung jumlah transaksi yang memuat semua item didalam kandidat k-itemset tersebut. Ini adalah juga ciri dari algoritma apriori dimana diperlukan penghitungan dengan cara seluruh database sebanyak k-itemset terpanjang

3. Tetapkan pola frekuensi tinggi. Pola frekuensi tinggi yang memuat $\mathrm{k}$ item atau $\mathrm{k}$-itemset ditetapkan dari kandidat k-itemset yang supportnya lebih besar dari minimum support. Bila tidak didapat pola frekuensi tinggi baru maka seluruh proses dihentikan. Bila tidak, maka k ditambah satu dan kembali bagian 1 .

\section{Rapid Miner}

Rapid Miner merupakan perangkat lunak yang dibuat oleh Dr. Markus Hofmann dari Institute of Technologi Blanchardstown dan Ralf Klinkenberg dari rapid-i.com dengan tampilan GUI (Graphical User Interface) sehingga memudahkan pengguna dalam menggunakan perangkat lunak ini. RapidMiner merupakan perangakat lunak yang bersifat terbuka (open source). RapidMiner adalah sebuah solusi untuk melakukan analisis terhadap data mining, text mining dan analisis prediksi. RapidMiner menggunakan berbagai teknik deskriptif dan prediksi dalam memberikan wawasan kepada pengguna sehingga dapat membuat keputusan yang paling baik (Afdal \& Rosadi, 2019).

\section{METODOLOGI PENELITIAN}

\section{Instrumen Penelitian}

Instrumen penelitian adalah aspek pengumpulan data yang dilakukan dalam penelitian ilmiah. Hasil instrumen penelitian ini kemudian dikembangkan atau dianalisa sesuai dengan metode penelitian yang akan diambil. Karena data yang di perlukan dalam penelitian ini adalah data kuantitatif yang di hitung dengan statistik dan menghasilkan deretan angka maka instrumen yang di lakukan penulis dengan melakukan pencatatan, wawancara informal dimana yang menjadi instrumen utama yaitu penulis sendiri karena penulis langsung yang terjun ke lapangan guna mengambil data primer yang di butuhkan dengan melakukan observasi.

\section{Metode Analisis Data}

Berikut ini yang digunakan untuk analisis data algoritma apriori :

A. Analisa Permasalahan PT. Natural Nusantara Menganalisa permasalahan yang akan di analisis dngan menggunakan metode algoritma apriori.

B. Analisis Pola Frekuensi Tinggi

Tahap ini mencari kombinasi item yang memenuhi syarat minimum dari nilai support dalam database. Nilai support sebuah item diperoleh dengan rumus berikut :

Support $(A)=\underline{\text { Jumlah Transaksi Mengandung A }}$ Total Transaksi

Sedangkan nilai support dari 2 item diperoleh rumus berikut :

Support $(A, B)=$ Jumlah Transaksi Mengandung AdanB

Total Transaksi

C. Pembentukan Aturan Asosiasi

Setelah semua pola frekuensi tinggi ditemukan, barulah dicari aturan assosiatif yang memenuhi syarat minimum untuk confidence dengan menghitung confidence aturan assosiatif A_B. Nilai confidence dari aturan A_B diperoleh dari rumus berikut:

$$
\begin{array}{lcc}
\text { Confidence } \\
(B \mid A)=
\end{array} \quad P \quad \begin{gathered}
\text { Jumlah Transaksi Mengandung } \\
\cline { 2 - 2 }
\end{gathered}
$$


D. Aturan Asosiasi Final

Dari analisis yang telah di lakukan dalam tahap ini akan terlihat asosiasi yang terbentuk dengan menggunakan perhitungan algoritma apriori.

E. Implementasi Algoritma Apriori pada RapidMiner

Setelah hasil perhitungan algoritma apriori di dapat dengan perhitungan manual maka akan lebih akurat dengan software RapidMiner. Dengan cara menginput tabel tabular ke dalam Ms.Excel yang kemudian di masukan ke software RapidMiner.

\section{HASIL DAN PEMBAHASAN}

Data transaksi penjualan produk akan terus bertambah setiap harinya dan menyebabkan penyimpanan data yang sangat besar. Kebanyakan data transaksi penjualan produk hanya dijadikan sebagai arsip saja tanpa dimanfaatkan dengan baik, maka diperlukan sebuah metode atau teknik yang dapat merubah data-data yang menumpuk tersebut menjadi informasi yang bermanfaat untuk pengambilan keputusan dengan menggunakan algoritma apriori untuk menghitung data penjualan produk kosmetik selama 6 bulan.

Daftar Produk ( Kategori Kosmetik )

Berikut ini adalah daftar produk berdasarkan kategori kosmetik yang akan dianalisis, dapat dilihat pada tabel dibawah ini :

Tabel 1. Daftar Produk

\begin{tabular}{|c|l|l|}
\hline \multicolumn{3}{|c|}{ TABEL DAFTAR PRODUK } \\
\hline No & \multicolumn{3}{|c|}{ Kategori ( Kosmetik ) } \\
\hline 1 & AYLA & AYLA BREAST CARE \\
\hline 2 & BWHITE & $\begin{array}{l}\text { BODY BUTER } \\
\text { WHITENING VIT E }\end{array}$ \\
\hline 3 & CHARCO & $\begin{array}{l}\text { ERSHALI CHARCOAL } \\
\text { SOAP }\end{array}$ \\
\hline 4 & COFC & $\begin{array}{l}\text { COLLAGEN } \\
\text { CLEANSER }\end{array}$ \\
\hline 5 & COSKIN & $\begin{array}{l}\text { COLLAGEN SKIN CARE } \\
\text { FACIAL SOAP ACNE }\end{array}$ \\
\hline 6 & EAAFS & $\begin{array}{l}\text { ERSHALI ANTI ARIGHTENING } \\
\text { EASHALI BOAP }\end{array}$ \\
\hline 8 & FISHCO & $\begin{array}{l}\text { ERSHALI FISH COLLAGEN } \\
\text { SOAP }\end{array}$ \\
\hline 9 & GAIA & $\begin{array}{l}\text { LOOKE HOLY LIP CREAM } \\
\text { GAIA }\end{array}$ \\
\hline 10 & GLOW & $\begin{array}{l}\text { MORESKIN CLEAN N } \\
\text { GLOW }\end{array}$ \\
\hline
\end{tabular}

\begin{tabular}{|c|c|c|}
\hline 11 & GRECE & GRECE BODY CRISTAL \\
\hline 12 & HBBHAP & $\begin{array}{l}\text { MS H\&B LOTION BREATH } \\
\text { HAPPINES }\end{array}$ \\
\hline 13 & HDE & $\begin{array}{ll}\text { HIDRATING } & \text { DIVINE } \\
\text { ESSENSE } & \\
\end{array}$ \\
\hline 14 & HEBE & $\begin{array}{l}\text { LOOKE HOLY LIP CREAM } \\
\text { HEBE }\end{array}$ \\
\hline 15 & HFRESH & MS H\&B OIL FRESH \\
\hline 16 & HROMAN & MS H\&B OIL ROMANTIC \\
\hline 17 & HSPORTY & MS H\&B OIL SPORTY \\
\hline 18 & IRENE & $\begin{array}{l}\text { LOOKE HOLY LIP CREAM } \\
\text { IRENE }\end{array}$ \\
\hline 19 & LC01MN & MS LIP CREAM 1-MERAH \\
\hline 20 & LC03MM & $\begin{array}{l}\text { MORESKIN LIP CREAM } 03 \\
\text {-MERAH MENYALA }\end{array}$ \\
\hline 21 & LC05MT & MS LIP CREAM 8-PINK \\
\hline 22 & LC07MB & $\begin{array}{l}\text { MORESKIN LIP CREAM - } \\
\text { MERAH BATA }\end{array}$ \\
\hline 23 & LC09CM & $\begin{array}{l}\text { MORESKIN LIP CREAM } 09 \\
\text {-COKLAT MENYALA }\end{array}$ \\
\hline 24 & LGLOSS & $\begin{array}{l}\text { MORESKIN } \\
\text { TRANSPARAN LIP }\end{array}$ \\
\hline 25 & LPOWDER & $\begin{array}{ll}\text { MORESKIN } & \text { LOOSE } \\
\text { POWDER } & \\
\end{array}$ \\
\hline 26 & LUNA & $\begin{array}{l}\text { LOOKE HOLY LIP CREAM } \\
\text { LUNA }\end{array}$ \\
\hline 27 & NATURE & $\begin{array}{ll}\text { PAKET } & \text { MORESKIN } \\
\text { NATURE } & \\
\end{array}$ \\
\hline 28 & ORLYNS & $\begin{array}{l}\text { ORLYN SHAMPO } \\
\text { AROMATHERAPY }\end{array}$ \\
\hline 29 & PEELING & ERSHALI PEELING SPRAY \\
\hline 30 & PGN & PASTA GIGI NASA \\
\hline 31 & SERGOLD & MORESKIN SERUM GOLD \\
\hline 32 & SKIN & $\begin{array}{ll}\text { PAKET } & \text { KECANTIKAN } \\
\text { MORESKIN } & \\
\end{array}$ \\
\hline 33 & SPCREAM & $\begin{array}{l}\text { MORESKIN STOMACH } \\
\text { CREAM }\end{array}$ \\
\hline 34 & SVITC30 & $\begin{array}{l}\text { MORESKIN SERUM VIT C } \\
30\end{array}$ \\
\hline 35 & THALIA & $\begin{array}{l}\text { LOOKE HOLY LIP CREAM } \\
\text { THALIA }\end{array}$ \\
\hline 36 & TRIPLE & $\begin{array}{l}\text { TRIPLE SIX HAIR TONIC } \\
\text { GINGSENG }\end{array}$ \\
\hline 37 & UNARM & MORESKIN UNDERARM \\
\hline 38 & XACNE & MORESKIN ANTI ACNE \\
\hline
\end{tabular}

\section{Pembentukan Itemset}

Proses pembentukan $\mathrm{C}_{1}$ atau disebut dengan 1 itemset dengan jumlah minimum support $=10 \%$ dengan rumus sebagai berikut: 
Support $(\mathrm{A})=\frac{\text { jumlah transaksi mengandung A }}{\text { total ransaksi }} \times 100 \%$

Tabel 2. Pembentukan Itemset

\begin{tabular}{|c|c|c|}
\hline \multicolumn{3}{|c|}{$\begin{array}{l}\text { Tabel Support dari setiap itemset minimum } \\
\qquad 10 \%\end{array}$} \\
\hline Itemset & Jumlah & Support \\
\hline AYLA & 21 & $12.1 \%$ \\
\hline BWHITE & 27 & $15.5 \%$ \\
\hline CHARCO & 44 & $25.3 \%$ \\
\hline $\mathrm{COFC}$ & 46 & $26.4 \%$ \\
\hline COSKIN & 32 & $18.4 \%$ \\
\hline EAAFS & 37 & $21.3 \%$ \\
\hline EBS & 45 & $25.9 \%$ \\
\hline FISHCO & 32 & $18.4 \%$ \\
\hline GAIA & 13 & $7.5 \%$ \\
\hline GLOW & 33 & $19.0 \%$ \\
\hline GRECE & 41 & $23.6 \%$ \\
\hline HBBHAP & 12 & $6.9 \%$ \\
\hline HDE & 21 & $12.1 \%$ \\
\hline HEBE & 13 & $7.5 \%$ \\
\hline HFRESH & 10 & $5.7 \%$ \\
\hline HROMAN & 7 & $4.0 \%$ \\
\hline HSPORTY & 8 & $4.6 \%$ \\
\hline IRENE & 14 & $8.0 \%$ \\
\hline LC01MN & 12 & $6.9 \%$ \\
\hline LC03MM & 26 & $14.9 \%$ \\
\hline LC05MT & 21 & $12.1 \%$ \\
\hline LC07MB & 28 & $16.1 \%$ \\
\hline LC09CM & 25 & $14.4 \%$ \\
\hline LGLOSS & 23 & $13.2 \%$ \\
\hline LPOWDER & 17 & $9.8 \%$ \\
\hline LUNA & 12 & $6.9 \%$ \\
\hline NATURE & 27 & $15.5 \%$ \\
\hline ORLYNS & 20 & $11.5 \%$ \\
\hline PEELING & 22 & $12.6 \%$ \\
\hline PGN & 58 & $33.3 \%$ \\
\hline SERGOLD & 30 & $17.2 \%$ \\
\hline SKIN & 19 & $10.9 \%$ \\
\hline SPCREAM & 35 & $20.1 \%$ \\
\hline SVITC30 & 24 & $13.8 \%$ \\
\hline THALIA & 18 & $10.3 \%$ \\
\hline TRIPLE & 31 & $17.8 \%$ \\
\hline UNARM & 30 & $17.2 \%$ \\
\hline XACNE & 35 & $20.1 \%$ \\
\hline
\end{tabular}

Dari proses pembentukan itemset dari Tabel 2 dengan minimum support $10 \%$, dapat diketahui yang memenuhi standart minimum support yaitu : AYLA, BWHITE, CHARCO, COFC, COSKIN, EAAFS, EBS, FISHCO, GLOW, GRECE, HDE, LC03MM, LC05MT, LC07MB, LC09CM, LGLOSS, NATURE, ORLYNS, PEELING, PGN, SERGOLD, SKIN, SPCREAM, SVITC30, THALIA, TRIPLE, UNARM, XACNE.

\section{Kombinasi 2 Itemset}

Proses pembentukan $\mathrm{C}_{2}$ atau disebut 2 itemset dengan jumlah minimum support $=10 \%$ dapat diselesaikan dengan rumus berikut:

Support $(A \cdot B)=P(A \cap B)$

Support $(\mathrm{A}, \mathrm{B})=\frac{\text { transaksi mengandung } \mathrm{A} \text { dan }}{\text { total transaksi }} \times 100 \%$ Tabel 3. Kombinasi 2 Itemset

\begin{tabular}{|c|c|c|}
\hline \multicolumn{3}{|c|}{ Tabel Support dari 2 Itemset minimum $10 \%$} \\
\hline Itemset & Jumlah & Suppor \\
\hline PGN, COFC & 24 & $13.8 \%$ \\
\hline PGN, EBS & 14 & $8.0 \%$ \\
\hline PGN, CHARCO & 14 & $8.0 \%$ \\
\hline PGN, GRECE & 19 & $10.9 \%$ \\
\hline PGN, EAAFS & 13 & $7.5 \%$ \\
\hline PGN, XACNE & 19 & $10.9 \%$ \\
\hline PGN, SPCREAM & 14 & $8.0 \%$ \\
\hline PGN, GLOW & 13 & $7.5 \%$ \\
\hline PGN, FISHCO & 12 & $6.9 \%$ \\
\hline PGN, TRIPLE & 11 & $6.3 \%$ \\
\hline PGN, UNARM & 12 & $6.9 \%$ \\
\hline PGN, LC07MB & 12 & $6.9 \%$ \\
\hline PGN, NATURE & 11 & $6.3 \%$ \\
\hline PGN, LC03MM & 14 & $8.0 \%$ \\
\hline PGN, LC05MT & 11 & $6.3 \%$ \\
\hline COFC, EBS & 15 & $8.6 \%$ \\
\hline COFC, CHARCO & 13 & $7.5 \%$ \\
\hline COFC, GRECE & 11 & $6.3 \%$ \\
\hline COFC, EAAFS & 14 & $8.0 \%$ \\
\hline COFC, XACNE & 9 & $5.2 \%$ \\
\hline COFC, SPCREAM & 16 & $9.2 \%$ \\
\hline COFC, GLOW & 9 & $5.2 \%$ \\
\hline COFC, FISHCO & 10 & $5.7 \%$ \\
\hline COFC, LC07MB & 10 & $5.7 \%$ \\
\hline COFC, LC03MM & 10 & $5.7 \%$ \\
\hline EBS, CHARCO & 27 & $15.5 \%$ \\
\hline EBS, GRECE & 13 & $7.5 \%$ \\
\hline EBS, EAAFS & 16 & $9.2 \%$ \\
\hline EBS, XACNE & 9 & $5.2 \%$ \\
\hline EBS, FISHCO & 20 & $11.5 \%$ \\
\hline EBS, TRIPLE & 10 & $5.7 \%$ \\
\hline EBS, BWHITE & 10 & $5.7 \%$ \\
\hline EBS, LC03MM & 9 & $5.2 \%$ \\
\hline CHARCO, GRECE & 12 & $6.9 \%$ \\
\hline CHARCO, EAAFS & 12 & $6.9 \%$ \\
\hline CHARCO, XACNE & 9 & $5.2 \%$ \\
\hline CHARCO, SPCREAM & 10 & $5.7 \%$ \\
\hline CHARCO, FISHCO & 23 & $13.2 \%$ \\
\hline
\end{tabular}

Dari proses pembentukan 2 itemset pada Tabel 3 dengan minimum support $10 \%$, dapat diketahui yang memenuhi standart minimum support yaitu :

1. PGN, COFC dengan support $13.8 \%$

2. PGN, GRECE dengan support $10.9 \%$

3. PGN, XACNE dengan support $10.9 \%$

4. EBS, CHARCO dengan support $15.5 \%$ 
5. EBS, FISHCO dengan support $11.5 \%$

6. CHARCO, FISHCO dengan support $13.2 \%$

\section{Pembentukan Aturan Asosiasi}

Setelah semua pola frekuensi tinggi ditemukan, barulah mencari aturan asosiasi yang memenuhi syarat minimum untuk confidence dengan menghitung confidence aturan asosiatif $\mathrm{A} \rightarrow \mathrm{B}$. Dengan minimum confidence $50 \%$.

Nilai aturan $\mathrm{A} \rightarrow \mathrm{B}$ diperoleh

Confidence $=\mathrm{P}(\mathrm{A}, \mathrm{B})$

$=\frac{\text { transaksi mengandung Adan }}{\text { total transaksi }} \times 100 \%$

Tabel 4. Pembentukan Aturan Asosiasi

\section{Tabel Perhitungan Aturan Assosiasi 50\%}

\begin{tabular}{|c|c|c|}
\hline Aturan & \multicolumn{2}{|c|}{ Confidence } \\
\hline $\begin{array}{l}\text { 1. Jika membeli THALIA, maka } \\
\text { akan membeli CHARCO }\end{array}$ & $9 / 18$ & $50.0 \%$ \\
\hline $\begin{array}{l}\text { 2. Jika membeli FISHCO, maka } \\
\text { akan membeli EBS, CHARCO }\end{array}$ & $16 / 32$ & $50.0 \%$ \\
\hline $\begin{array}{l}\text { 3. Jika membeli COFC, maka } \\
\text { akan membeli PGN }\end{array}$ & $24 / 46$ & $52.2 \%$ \\
\hline $\begin{array}{l}\text { 4. Jika membeli CHARCO, maka } \\
\text { akan membeli FISHCO }\end{array}$ & $23 / 44$ & $52.3 \%$ \\
\hline $\begin{array}{l}\text { 5. Jika membeli LC05MT, maka } \\
\text { akan membeli PGN }\end{array}$ & $11 / 21$ & $52.4 \%$ \\
\hline $\begin{array}{l}\text { 6. Jika membeli LC03MM, maka } \\
\text { akan membeli PGN }\end{array}$ & $14 / 26$ & $53.8 \%$ \\
\hline $\begin{array}{l}\text { 7. Jika membeli XACNE, maka } \\
\text { akan membeli PGN }\end{array}$ & $19 / 35$ & $54.3 \%$ \\
\hline $\begin{array}{l}\text { 8. Jika membeli COFC, } \\
\text { SPCREAM, maka akan membeli } \\
\text { PGN }\end{array}$ & $9 / 16$ & $56.2 \%$ \\
\hline $\begin{array}{l}\text { 9. Jika membeli EBS, EAAFS, } \\
\text { maka akan membeli CHARCO }\end{array}$ & $9 / 16$ & $56.2 \%$ \\
\hline $\begin{array}{l}\text { 10. Jika membeli EBS, EAAFS, } \\
\text { maka akan membeli FISHCO }\end{array}$ & $9 / 16$ & $56.2 \%$ \\
\hline $\begin{array}{l}\text { 11. Jika membeli EBS, } \\
\text { CHARCO, maka akan membeli } \\
\text { FISHCO }\end{array}$ & $16 / 27$ & $59.3 \%$ \\
\hline $\begin{array}{l}\text { 12. Jika membeli EBS, maka } \\
\text { akan membeli CHARCO }\end{array}$ & $27 / 45$ & $60.0 \%$ \\
\hline $\begin{array}{l}\text { 13. Jika membeli CHARCO, } \\
\text { maka akan membeli EBS }\end{array}$ & $27 / 44$ & $61.4 \%$ \\
\hline $\begin{array}{l}\text { 14. Jika membeli FISHCO, maka } \\
\text { akan membeli EBS }\end{array}$ & $20 / 32$ & $62.5 \%$ \\
\hline $\begin{array}{l}\text { 15. Jika membeli PGN, } \\
\text { SPCREAM, maka akan membeli } \\
\text { COFC }\end{array}$ & $9 / 44$ & $64.3 \%$ \\
\hline $\begin{array}{l}\text { 16. Jika membeli EBS, GRECE, } \\
\text { maka akan membeli CHARCO }\end{array}$ & $9 / 13$ & $69.2 \%$ \\
\hline $\begin{array}{l}\text { 17. Jika membeli CHARCO, } \\
\text { FISHCO, maka akan membeli } \\
\text { EBS }\end{array}$ & $16 / 23$ & $69.6 \%$ \\
\hline $\begin{array}{l}\text { 18. Jika membeli PGN, EBS, } \\
\text { maka akan membeli CHARCO }\end{array}$ & $10 / 14$ & $71.4 \%$ \\
\hline
\end{tabular}

\begin{tabular}{|c|c|c|}
\hline $\begin{array}{l}\text { 19. Jika membeli PGN, } \\
\text { CHARCO, maka akan membeli } \\
\text { EBS }\end{array}$ & $10 / 14$ & $71.4 \%$ \\
\hline $\begin{array}{l}\text { 20. Jika membeli FISHCO, maka } \\
\text { akan membeli CHARCO }\end{array}$ & $23 / 32$ & $71.9 \%$ \\
\hline $\begin{array}{l}21 . \quad \text { Jika } \\
\text { CHARCO,GRECE, maka akan } \\
\text { membeli EBS }\end{array}$ & $9 / 12$ & $75.0 \%$ \\
\hline $\begin{array}{l}\text { 22. Jika membeli } \text { CHARCO, } \\
\text { EAAFS, maka akan membeli } \\
\text { EBS }\end{array}$ & $9 / 12$ & $75.0 \%$ \\
\hline $\begin{array}{l}\text { 23. Jika membeli EBS, FISHCO, } \\
\text { maka akan membeli CHARCO }\end{array}$ & $16 / 20$ & $80.0 \%$ \\
\hline 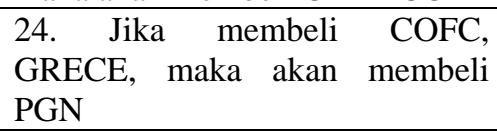 & $9 / 11$ & $81.8 \%$ \\
\hline $\begin{array}{l}25 . \quad \text { Jika membeli } \\
\text { FISHCO, maka akan membeli } \\
\text { EBS }\end{array}$ & $9 / 10$ & $90.0 \%$ \\
\hline
\end{tabular}

Berdasarkan pembentukan aturan assosiasi pada table 4 diatas, maka semuanya memenuhi standart minimum confidence $50 \%$.

\section{Implementasi Sistem}

Hasil dari pengujian model yang dilakukan adalah implementasi data mining penjualan produk kosmetik pada PT. Natural Nusantara menggunakan algoritma apriori. Dengan min. support $10 \%$ dan minimum confidence 50\%, hasil rule yang terbentuk berjumlah 7 rule yang dapat dilihat pada gambar dibawah ini:

Formula-formula pada algoritma apriori sudah dirangkum dalam model algoritma apriori pada framework RapidMiner 5.3. Formulanya sebagai berikut :
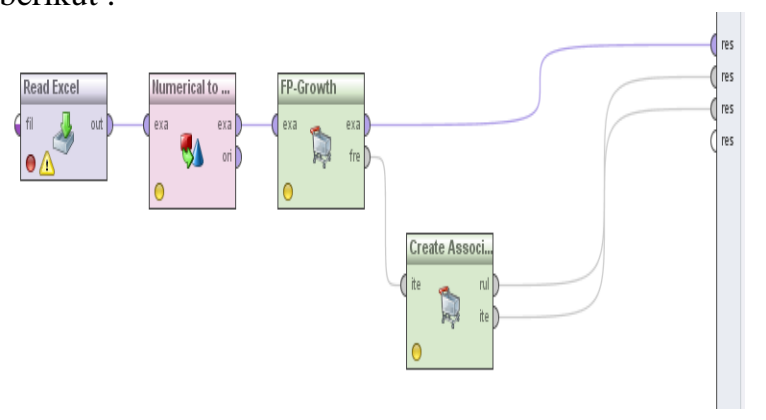

Gambar 1. Desain Model

Maka didapat hasil rule yang terbentuk menjadi 7 rule dari hasil RapidMiner 5.3 sebagai berikut :

\begin{tabular}{|c|c|c|c|c|}
\hline \multirow{2}{*}{\multicolumn{2}{|c|}{ 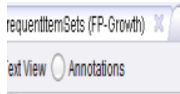 }} & \multicolumn{3}{|c|}{ 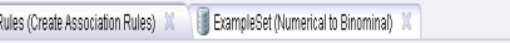 } \\
\hline & & & & X \\
\hline No. & Premises & Condusion & Support Confid & Lapla. Gain p-s Lif Coni. \\
\hline 1 & COFC & PGN & $0.138 \quad 0.522$ & $0.000-0.3910 .0501 .5651 .394$ \\
\hline & CHARCO & FSHCO & $0.132 \quad 0.523$ & $0.004-0.3740 .0862 .842 \quad 1.710$ \\
\hline 3 & XACNE & PGN & $0.109 \quad 0.543$ & $0.923-0.2930 .0421 .6291 .458$ \\
\hline 4 & EBS & CHARCO & $0.155 \quad 0.600$ & $0.918-0.36200902 .3731 .868$ \\
\hline 5 & CHARCO & EBS & 0.1550 .614 & $0.922-0.3510 .0902 .3731 .919$ \\
\hline 6 & FISHCO & EBS & $0.115 \quad 0.625$ & $0.942-0.2530 .0672 .4171 .977$ \\
\hline 7 & FISHCO & CHARCO & $0.132 \quad 0.719$ & $0.956-0.2360 .0862 .8422 .656$ \\
\hline
\end{tabular}




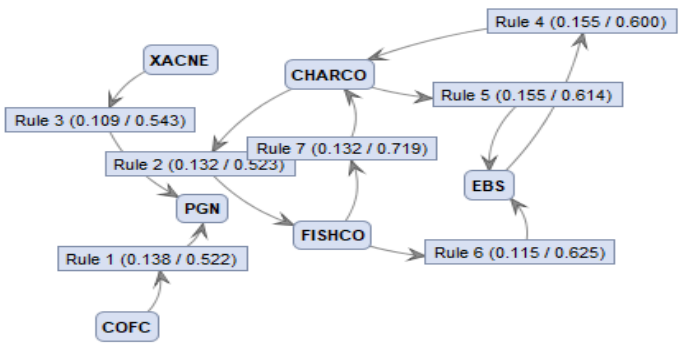

Gambar 3. Tampilan Graph View

Berdasarkan Assosiasi Final dan Graph View diatas, dapat disimpulkan ada 7 rule yaitu

1. Rule 1 ( COFC, PGN )

Support : $13.8 \%$, Confidence : $52.2 \%$, Lift : 1.565

2. Rule 2 ( CHARCO, FISHCO )

Support : $13.2 \%$, Confidence : $52.3 \%$, Lift : 2.842

3. Rule 3 (XACNE, PGN )

Support : $10.9 \%$, Confidence : $54.3 \%$, Lift : 1.629

4. Rule 4 ( EBS, CHARCO )

Support : $15.5 \%$, Confidence : $60.0 \%$, Lift : 1.868

5. Rule 5 (CHARCO, EBS )

Support : $15.5 \%$, Confidence : $61.4 \%$, Lift : 2.373

6. Rule 6 (FISHCO, EBS )

Support : $11.5 \%$, Confidence : $62.5 \%$, Lift : 2.373

7. Rule 7 ( FISHCO, CHARCO )

Support : $13.2 \%$, Confidence : $71.9 \%$, Lift : 2.842

\section{KESIMPULAN}

Setelah melakukan pengujian dengan cara perhitungan manual dan perhitungan menggunakan software RapidMiner 5.3, dapat diketahui bahwa hasil yang diperoleh dari perhitungan manual sama dengan perhitungan menggunakan software RapidMiner 5.3. Pola asosiasi yang terbentuk dengan nilai minimum support $10 \%$ dan nilai minimum confidence 50\% menghasilkan 7 aturan asosiasi. Dan strong rules yang didapatkan adalah Jika membeli CHARCO maka akan membeli EBS dengan nilai support $15.5 \%$ dan nilai minimum confidence $61.4 \%$. Dengan diketahui produk yang sering dibeli maka perusahaan dapat mengembangkan strategi pemasaran dan mengatur stok barang agar tidak terjadi penumpukan. Penggunaan algoritma apriori dengan metode FPGrowth dapat membantu pihak manajemen untuk meletakkan barang yang biasa dibeli oleh konsumen, sehingga memudahkan konsumen untuk dapat membeli barang tersebut.

\section{Saran}

Aspek Manajerial

Penggunaan algoritma apriori dengan metode FPGrowth dapat membantu pihak manajemen untuk meletakkan barang yang biasa dibeli oleh konsumen, sehingga memudahkan pelanggan untuk membeli barang tersebut. Metode FP-Growth dapat membantu pihak manajemen untuk memantau stok barang yang sering dibeli oleh konsumen sehingga tidak akan terjadi kelangkaan.

\section{Aspek Sistem}

Sistem yang ada harus lebih detail terhadap transaksi penjualan supaya dapat mempermudah mencari data. Aspek Penelitian Untuk peneliti selanjutnya diharapkan melanjutkan penelitian ini apakah produk yang sering dibeli secara bersamaan ditempatkan berdekatan berpengaruh terhadap meningkatnya pola pembelian konsumen. Sebaiknya objek penelitian tidak hanya mencakup 6 bulan saja tetapi bisa setahun kebelakang agar data bisa lebih akurat.

\section{REFERENSI}

Afdal, M., \& Rosadi, M. (2019). PENERAPAN ASSOCIATION RULE MINING UNTUK ANALISIS. 5(1), 99-108.

Purnia, D. S., \& Warnilah, A. I. (2017). Implementasi Data Mining Pada Penjualan Kacamata Menggunakan Algoritma Apriori. IJCIT (Indonesian Journal ON COmputr and Information Technologi), 2(2), 31-39. Retrieved from http://ejournal.bsi.ac.id/ejurnal/index.php/ijcit/ article/view/2776

Sikumbang, E. D. (2018). Penerapan Data Mining Dengan Algoritma Apriori. Jurnal Teknik Komputer AMIK BSI (JTK), 9986(September), $1-4$.

\section{PROFIL PENULIS}

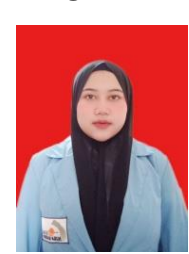

Penulis pertama bernama Fajar Adhinda Kusuma Wardani yang merupakan mahasiswa tingkat akhir STMIK Nusa Mandiri dan juga Alumni Bina Sarana Informatika.

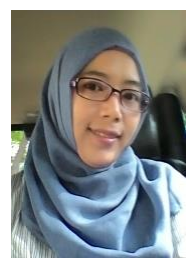

Penulis kedua bernama Titin Kristiana, yang memperoleh gelar Master Komputer (M.Kom) Jurusan Sistem Informasi Manajemen Program Pasca Sarjana STMIK Nusa Mandiri. Lulus pada tahun 2012. Saat ini menjadi dosen di STMIK

Nusa Mandiri. 